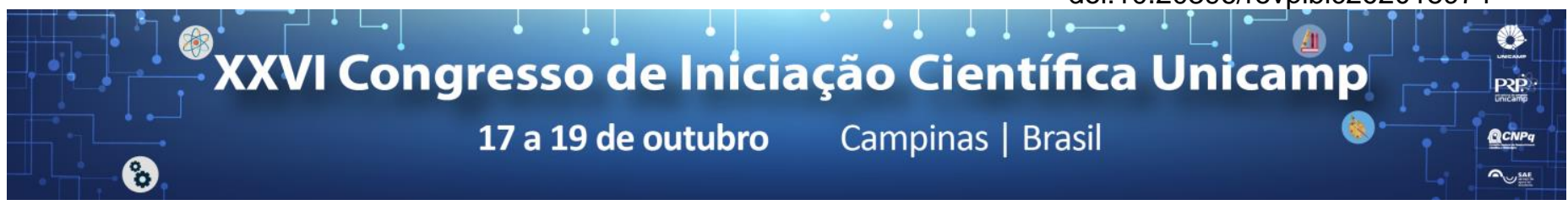

\title{
"Relação entre limiar basal de resposta pulpar a estímulo elétrico e sensibilidade a pressão na pele"
}

\section{Maria Luiza Justiniano Svicero*, Klinger de Souza Amorim, Maria Cristina Volpato e Francisco Carlos Groppo.}

\begin{abstract}
Resumo
O objetivo desse trabalho foi estudar a correlação entre o limiar de resposta ao estímulo elétrico aplicado em dentes com o limiar de sensibilidade cutânea e na mucosa. A sensibilidade à dor nos indivíduos foi observada pelo limiar de resposta ao estímulo elétrico aplicado em dentes incisivos superiores e o limiar de sensibilidade cutânea e na mucosa também foram obtidos. Para este ensaio, os voluntários foram submetidos ao teste com algesímetro de von Frey eletrônico para determinar a força (em Newtons) aplicada. Este teste foi realizado em 6 pontos da palma da mão, nas bochechas direita e esquerda, na gengiva esquerda e direita, língua e mento. Os resultados foram submetidos ao teste de Friedman para observar o efeito da sessão e comparar as sensibilidades em cada estrutura avaliada. $O$ teste de correlação de Spearman foi usado para observar a correlação entre os dois ensaios. A sensibilidade da face não diferiu entre as sessões para nenhuma das estruturas observadas. De uma forma geral, as medidas observadas para bochecha foram maiores $(p<0.001)$ do que nas demais estruturas. As medidas observadas para o mento foram maiores do que aquelas da gengivas e língua, sendo que estas não diferiram significativamente entre si. Não houve influência das sessões nos valores ( $p>0.05$ ) observados para os pontos da mão, mas o ponto 3 apresentou menores valores $(p<0.01)$ do que os pontos $1,2,5$ e 6 , não diferindo do ponto 4 . A sensibilidade pulpar dos dentes não sofreu influência $(p=0.1745)$ da sessão. Houve correlação excelente para os valores de sensibilidade entre as bochechas, entre as gengivas, entre todos os pontos medidos na mão, e entre o mento e as bochechas. As bochechas apresentaram boa correlação com a língua e todos os pontos da mão, mas a correlação com os dentes e gengivas foi fraca. Os dentes mostraram correlação boa entre si, mas fraca com todas as demais estruturas. Concluímos que houve fraca correlação entre a sensibilidade pulpar e a sensibilidade cutânea medida em outros pontos da face e da mão.
\end{abstract}

Palavras-chave: Estímulo elétrico em dentes, sensibilidade à dor, limiar de sensibilidade cutânea.

\section{Introdução}

O diagnóstico da dor odontogênica, causada pela ativação de nociceptores pulpares ou do ligamento periodontal, é um desafio clínico. O limiar de dor sob pressão avalia a presença de neuropatias usualmente na pele. São poucos os estudos que relacionam os diferentes métodos de medição da sensibilidade dolorosa. Assim, o presente estudo observou a correlação entre a resposta dolorosa à pressão e a resposta pulpar em indivíduos saudáveis.

\section{Resultados e Discussão}

Em duas sessões foram feitos 2 ensaios. No Ensaio 1 foi avaliado o limiar de resposta ao estímulo elétrico aplicado nos dentes 11 e 21 e no ensaio 2, 6 pontos da mão, bochechas direita e esquerda, gengiva direita e esquerda, mento e língua foram usados para obter o limiar de sensibilidade cutânea e na mucosa. Para observar a correlação de ambos os ensaios, foi utilizado o teste de Spearman. A sensibilidade da face não foi alterada entre as sessões. As medidas observadas para a bochecha foram maiores $(p<0.001)$ do que nas demais estruturas na face. Não houve influência das sessões nos valores ( $p>0.05$ ) observados nos pontos da mão, contudo, o ponto 3 apresentou valores menores $(p<0.01)$ do que os demais. A sensibilidade pulpar nos dentes 11 e 21 não foi influenciada $(p=0.1745)$ pela sessão. A correlação dos valores obtidos entre os lados direto e esquerdo das bochechas, da gengiva, entre os pontos da mão, e entre o mento $e$ as bochechas, foi excelente. As bochechas apresentaram boa correlação com a língua e com os pontos da mão, mas a correlação com os dentes e gengiva, foi fraca. Os dentes apresentaram boa correlação entre si, porém, fraca quando comparado às demais estruturas.
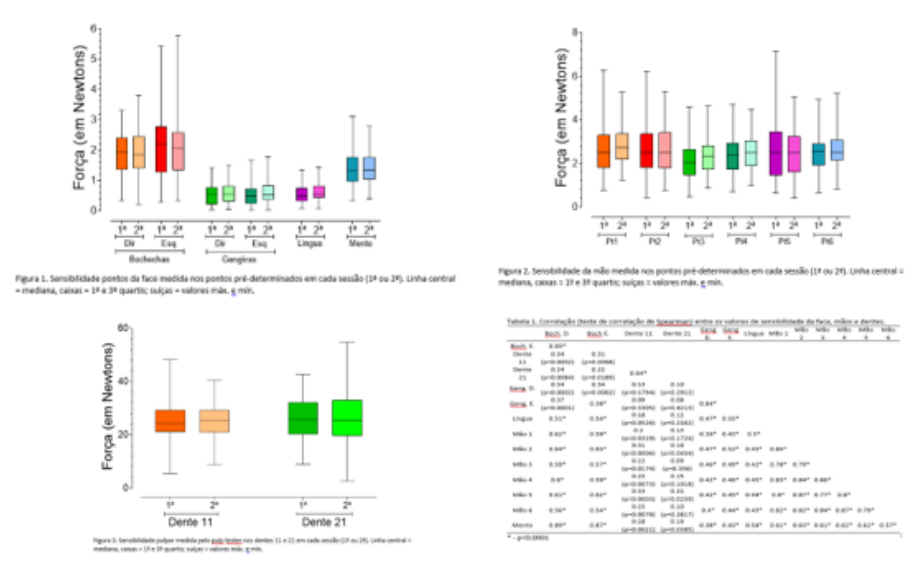

\section{Conclusões}

Houve fraca correlação entre a sensibilidade pulpar e a sensibilidade cutânea medida em outros pontos da face e da mão.

\section{Agradecimentos}

Ao PIBIC, Prof. Francisco C. Groppo e ao Klinger de Souza Amorim por toda orientação e suporte durante a pesquisa.

\section{Referências}

Liu R, Gu X, Zhang J, Yu L, Chen W, Wang K, Svensson P. Test-retest reliability of a new technique with pressure algometry applied to teeth in healthy Chinese individuals. Eur J Oral Sci. 2016;124(3):259-65.

Cooley RL, Stilley J, Lubow RM. Evaluation of a digital pulp tester. Oral Surg Oral Med Oral Pathol. 1984;58(4):437-42. 